DOI: 10.12731/2227-930X-2017-3-26-45

УДК 379.85

\title{
МНОГОЦЕЛЕВОЙ ПОДХОД К ОЦЕНКЕ ИННОВАЦИОННОГО ПОТЕНЦИАЛА ОРГАНИЗАЦИЙ ИНДУСТРИИ ТУРИЗМА
}

\section{Левченко Т.П., Вареников В.А.}

Говоря об инновачиях в организачиях индустрии туризма в иелом, и в гостиничном бизнесе, в частности, как правило, подразумевают мероприятия системного характера, обладающие качественной новизной, нацеленные на достижение позитивных сдвигов, устойчивого функционирования и динамичного развития. Наряду с общеткономическими факторами, обусловливающими неравномерность спроса на услуги гостиничного бизнеса, это объясняется и резким возрастанием зависимости их туристско-рекреационных возможностей от инновачионного потенцииала (ИП), способности адаптироваться к сложной конкурентной среде.

В статье рассмотрен многоиелевой подход к исследованию инновационного потенщиала организаџий индустрии туризма. Его суть заключается в том, что выбор структурных элементов с точки зрения их иенности и значимости (в том или ином сочетании) не может устанавливаться априори, без достаточно объективного их анализа по ряду наиболее важных для достижения поставленных иелей критериев. Проведен диагностический анализ и оченка инновационного потенциала нескольких гостиничных организаций с позиций многочелевого подхода.

Цель - обоснование оценки инновационного потенциала организаций индустрии туризма с позиции многоцелевого подхода.

Метод или методология проведения работы: в статье использовались экономико-математические методы анализа.

Результаты: обосновано использование рассматриваемого методического подхода, проведена оценка инновационного потенцчиала ряда организациий индустрии туризма. 
Область применения результатов: полученные результаты иелесообразно применять экономическими субъектами, осуществляюшими деятельность в сфере туризма, в частности в гостиничном бизнесе.

Ключевые слова: инновации; инноваччионный потенцииал; индустрия туризма; многочелевой подход.

\section{A MULTI-OBJECTIVE APPROACH \\ TO THE EVALUATION OF INNOVATIVE POTENTIAL OF THE TOURISM INDUSTRY ORGANIZATIONS}

\section{Levchenko T.P., Varenikov V.A.}

Speaking about innovation in the tourism industry and hotel business, in particular, it usually means events of a systemic nature, with quality novelty, aimed at achieving positive changes, stable functioning and dynamic development. Along with general economic factors that determine the uneven demand for services of hospitality, it is explained by the sharp increase in dependence of their tourism and recreational opportunities from innovative potential (IP), capability of adapting to challenging competitive environment.

The article considers a multi-objective approach to the study of the innovative potential of the tourism industry organizations. Its essence lies in the fact that the choice of the structural elements from the point of view of their value and importance (in any combination) cannot be established a priori, without sufficient objective analysis on some of the more important criteria for achieving the goals. A diagnostic analysis and evaluation of the innovation potential of several hotel organizations from the standpoint of a multi-purpose approach is performed.

Keywords: innovation; innovation potential; tourism industry; a multi-objective approach.

Теоретические и практические вопросы оценки инновационного потенциала хозяйствующих субъектов различного уровня и 
специализации находят отражение в работах многих российских исследователей.

Публикации Ю.А. Дорошенко, И.В. Соминой, В.Г. Матвейкина, С.И. Дворецкого, Л.В. Минько, В.П. Тарасова, Л.Н. Чайниковой, О.И. Летуновой, Л.Э. Морозовой, О.А. Бортник, И.С Кравчука, Р.А. Фатхутдинова и др. раскрывают оценку инновационного потенциала с позиции разных подходов, как количественных, так и качественных. Наиболее часто рассматриваются следующие подходы:

- выведение интегрального показателя;

- рейтингование;

- метод главных компонент;

- бальная оценка;

- опросы экспертов.

Отдавая должное безусловной значимости указанных методик в изучении теоретических и практических аспектов исследуемого понятия, считаем необходимым отметить, что дальнейшего рассмотрения и совершенствования требуют сами подходы, используемые оценочные показатели и алгоритмы оценки инновационного потенциала организаций с учетом специфики индустрии туризма и гостиничного бизнеса.

Отсутствие единого понимания в вопросах методического обеспечения оценки инновационного потенциала гостиничных организаций, а также нехватка статистических данных затрудняют теоретические и практические исследования в данной области. Вследствие этого вопросы оценки инновационного потенциала гостиничных организаций представляют существенный научный интерес.

Многоцелевой подход подразумевает в первую очередь исследование ценности самого инновационного потенциала, формирующего процессы внедрения инновационных решений организаций индустрии туризма $[1 ; 12]$. Значимость или ценность инновационного потенциала возможно определить по следующей формуле [6]:

$$
Q_{t}=E N P_{t} S(y)-E N P_{t o} \times \mathrm{e}^{-r} \times S(z),(1)
$$

где $Q$ - ценность инновационного потенциала туристской организации в $t$-м периоде; 
$E N P, E N P_{t o}$ - фактическая чистая и ожидаемая прибыль туристской организации в $t-\mu$ периоде;

$S(y), S(z)$ - стандартизированная функция нормального распределения чисел $\mathrm{y}, \mathrm{z}$;

$r$ - безрисковая ставка, под которой понимается ставка дисконтирования, равная доходности безрисковых вложений.

Многоцелевой подход предполагает также эффективный режим функционирования организаций индустрии туризма, который может складываться из концептуальной, конструктивной и операциональной моделей $[2 ; 15]$, то есть оценка инновационного потенциала производится по схеме: ресурс (Р) - функция (Ф) -направление деятельности (Д) [3;11].

Как отмечает в своей работе Н.Н. Погостинская, для формирования концептуальной модели оценки инновационного потенциала необходима реализация трёх последовательных шагов [9]:

- концептуализация;

- формализация;

- операционализация.

Упорядоченные системные характеристики организации без конкретного указания показателей, которые отражают их, формируют основу конструктивной модели. Операциональная модель опирается на формирование конкретных показателей динамического норматива [10]. Оценку ИП организации индустрии туризма, по нашему мнению, должно сопровождать использование операционной модели, требующей формирования динамических показателей.

Для проведения комплексной оценки ИП сравнение на основе одного критерия можно охарактеризовать как очевидно недостаточное. Развернутый экономический анализ подразумевает многокритериальное сравнение экономических субъектов. Важно отметить, что определенное количество показателей могут быть неравнозначными, в частности несоизмеримыми или разнонаправленными [8].

Диагностический анализ и оценка инновационного потенциала организации с позиций многоцелевого подхода подразумевает 
прохождения нескольких этапов [4]. Начальным этапом является формализация динамического критерия. Его формальное отражение будет заключаться в критериальном порядке движения показателей, которые были отобраны для анализа ИП. Критериальный порядок, то есть цель первого уровня, представлен в виде ряда с упорядоченными в соответствии с выбранным критерием показателями:

- основных экономических процессов;

- вспомогательных экономических процессов;

- процессов осуществления инновационной деятельности.

Включенные в перечень показатели, как уже было отмечено, не однородны по единицам измерения (могут быть натуральными, стоимостными и т.д.). Необходимо определить динамические критерии, которые будут наиболее полно характеризовать развитие организаций индустрии туризма.

Динамические критерии оценки ИП организации индустрии туризма могут быть разделены на несколько групп показателей в соответствии с поставленными целями:

- основные показатели (цель №1 - отразить основные экономические процессы организации);

- показатели обеспечения (цель №2 - охарактеризовать вспомогательные экономические процессы организации);

- показатели эффективности осуществления инновационной деятельности (цель №3 - оценить успешность реализации инновационного потенциала).

Достижение поставленных целей, по нашему мнению, должно быть сопряжено с оценкой соответствующих им уровней ресурсного обеспечения (рис. 1).

Хозяйствующие субъекты индустрии туризма будут рассмотрены нами на примере организаций гостиничного бизнеса г. Сочи. Рассмотрим блок показателей, характеризующих ИП гостиничных организаций (рис. 2).

На основании проведенного авторами математического моделирования путем сопоставления динамических показателей 
инновационного потенциала и уровня ресурсного обеспечения целевых направлений его оценки нами предлагается сформировать карту силового поля, позволяющую оптимизировать управленческие решения путем выбора наиболее приоритетных направлений [7].

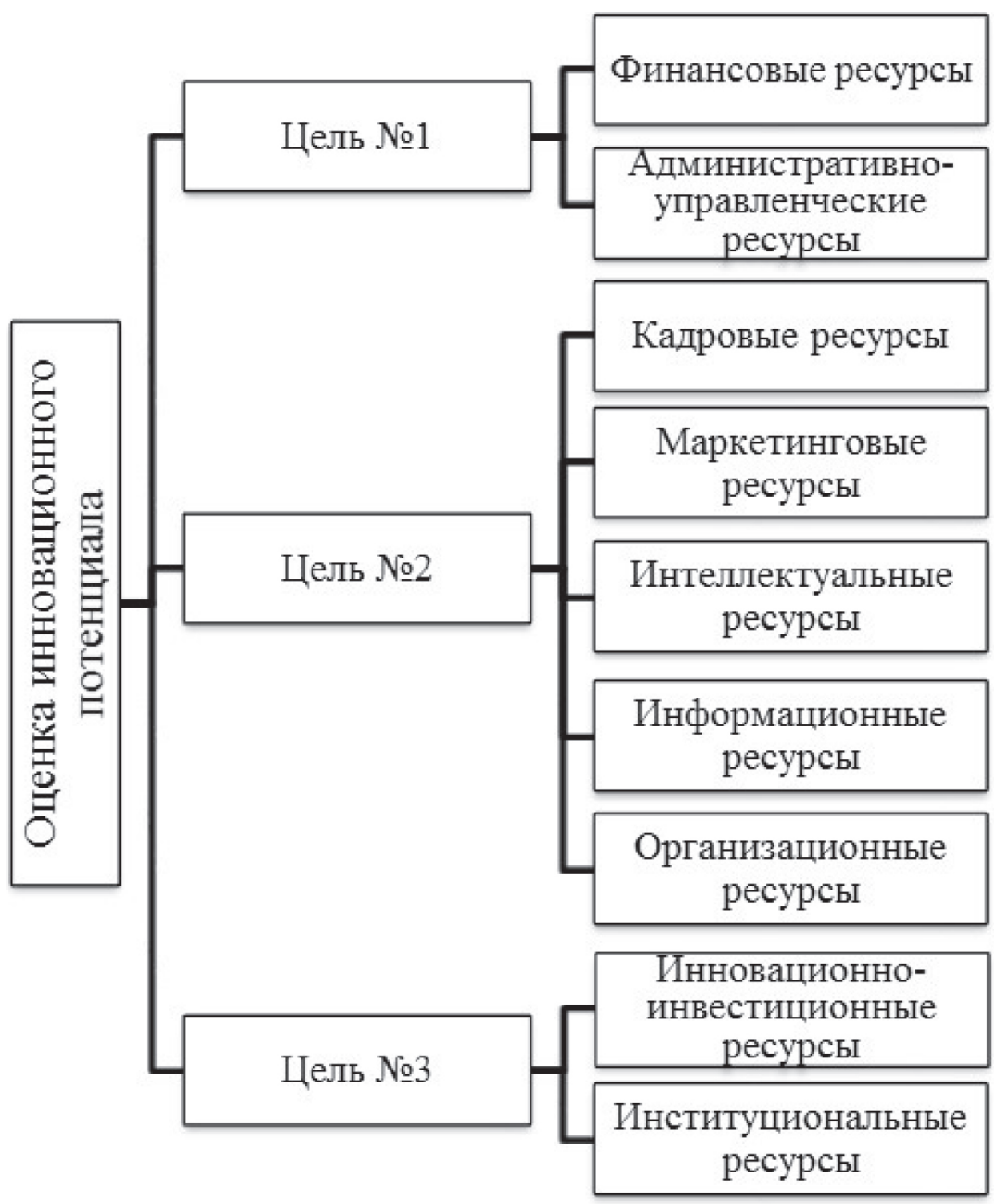

Рис. 1. Ресурсное обеспечение целевых направлений оценки ИП организаций 


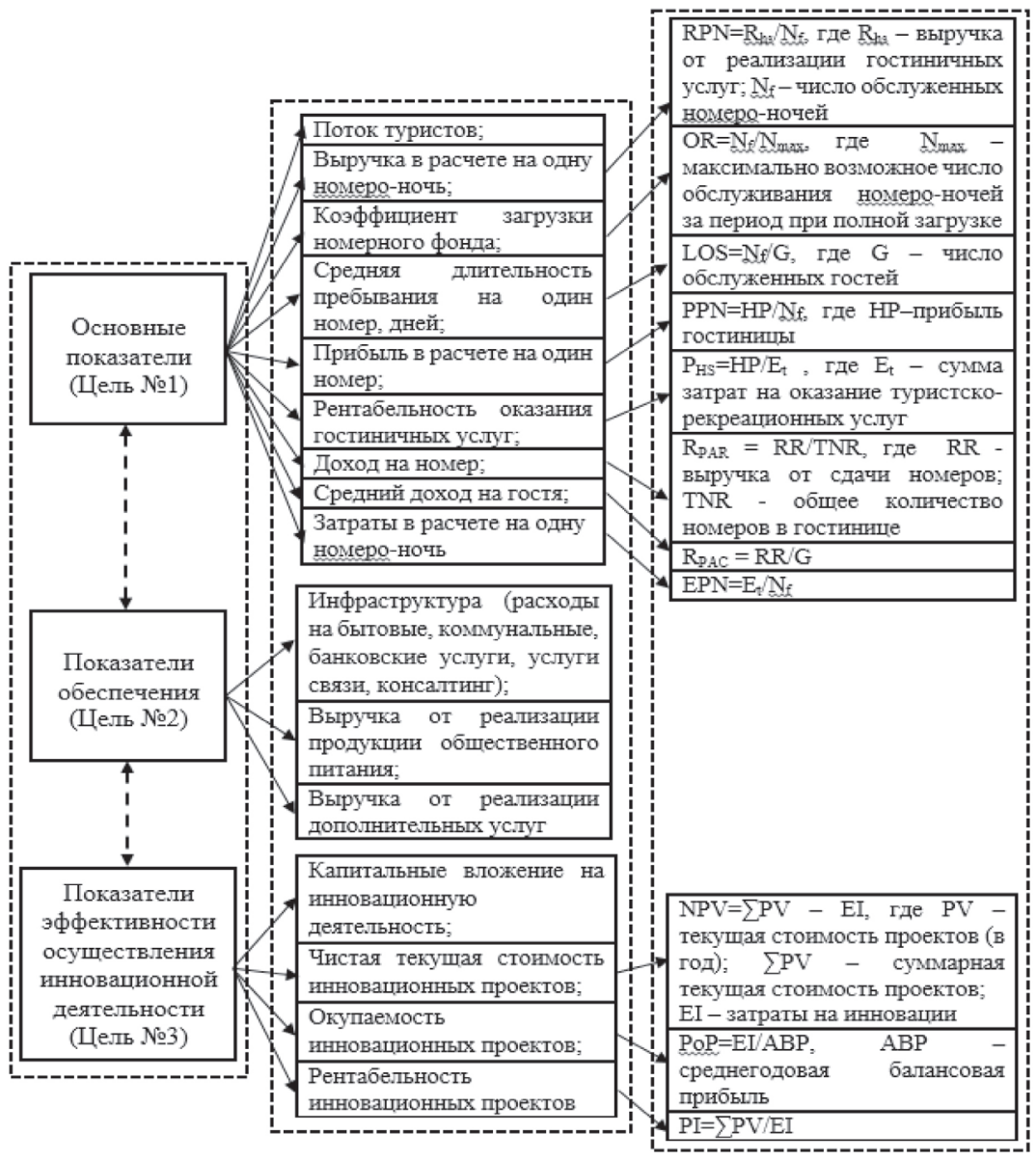

Рис. 2. Показатели, характеризующие инновационный потенциал гостиничных организаций

Как видно из представленной карты силового поля, инновационные, административно-управленческие и финансовые ресурсы можно детерминировать как наиболее значимые для гостиничных организаций. На основании данной карты руководство имеет возможность определить основные приоритеты использования и оценки инновационного потенциала. 
Таблица 1.

Карта силового поля инновационного потенциала гостиничных организаций

\begin{tabular}{|c|c|c|c|c|c|c|c|c|c|c|c|}
\hline & & \multicolumn{8}{|c|}{$\begin{array}{l}\text { Ресурсное обеспечение гостиничной } \\
\text { организации }\end{array}$} & \multirow[b]{2}{*}{ 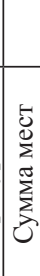 } & \\
\hline & & 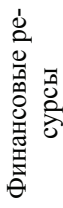 & 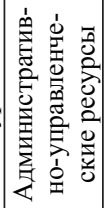 & 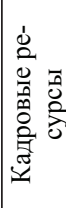 & 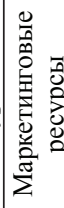 & 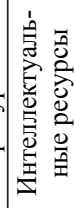 & 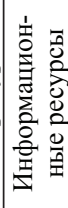 & 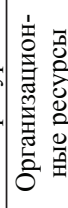 & 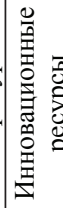 & & \\
\hline \multirow{19}{*}{ 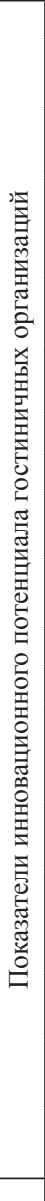 } & Поток туристов & 6 & 8 & 7 & 7 & 5 & 4 & 5 & 4 & 46 & 1 \\
\hline & $\begin{array}{l}\text { Выручка в расчете на } 1 \\
\text { номеро-ночь }\end{array}$ & 2 & 7 & 3 & 2 & 1 & 2 & 0 & 6 & 23 & 16 \\
\hline & \begin{tabular}{|l|} 
Коэффициент загрузки \\
номерного фонда \\
\end{tabular} & 3 & 6 & 1 & 8 & 5 & 4 & 6 & 3 & 36 & 7 \\
\hline & $\begin{array}{l}\text { Средняя длительность } \\
\text { пребывания на } 1 \text { номер, } \\
\text { дней }\end{array}$ & 1 & 6 & 3 & 5 & 2 & 1 & 7 & 6 & 31 & 9 \\
\hline & $\begin{array}{l}\text { Прибыль в расчете на } 1 \\
\text { номер }\end{array}$ & 4 & 6 & 1 & 4 & 2 & 2 & 3 & 5 & 27 & 12 \\
\hline & \begin{tabular}{|l|} 
Рентабельность оказания \\
гостиничных услуг
\end{tabular} & 1 & 7 & 0 & 5 & 2 & 1 & 2 & 7 & 25 & 14 \\
\hline & Доход на номер & 1 & 5 & 1 & 1 & 3 & 2 & 4 & 5 & 22 & 17 \\
\hline & Средний доход на гостя & 2 & 7 & 1 & 3 & 2 & 4 & 5 & 6 & 30 & 10 \\
\hline & $\begin{array}{l}\text { Затраты в расчете на } 1 \\
\text { номеро-ночь }\end{array}$ & 9 & 8 & 0 & 0 & 0 & 2 & 0 & 5 & 24 & 15 \\
\hline & $\begin{array}{l}\text { Затраты на коммунальные } \\
\text { услуги }\end{array}$ & 10 & 5 & 0 & 0 & 0 & 0 & 0 & 6 & 21 & 18 \\
\hline & Объем услуг связи & 9 & 4 & 0 & 2 & 1 & 10 & 0 & 4 & 30 & 10 \\
\hline & Затраты на прочие услуги & 9 & 7 & 0 & 2 & 4 & 6 & 2 & 5 & 35 & 8 \\
\hline & $\begin{array}{l}\text { Выручка от реализации } \\
\text { продукции общественного } \\
\text { питания }\end{array}$ & 8 & 7 & 5 & 4 & 6 & 2 & 5 & 4 & 41 & 3 \\
\hline & $\begin{array}{l}\text { Выручка от реализации } \\
\text { дополнительных услуг }\end{array}$ & 6 & 7 & 4 & 3 & 6 & 4 & 2 & 6 & 38 & 5 \\
\hline & $\begin{array}{l}\text { Капитальные вложение } \\
\text { на инновационную } \\
\text { деятельность }\end{array}$ & 10 & 6 & 0 & 3 & 7 & 5 & 3 & 10 & 44 & 2 \\
\hline & $\begin{array}{l}\text { Чистая текущая стоимость } \\
\text { инновационных проектов }\end{array}$ & 3 & 2 & 0 & 0 & 6 & 4 & 2 & 9 & 26 & 13 \\
\hline & $\begin{array}{l}\text { Окупаемость } \\
\text { инновационных проектов }\end{array}$ & 7 & 5 & 2 & 4 & 6 & 1 & 2 & 10 & 37 & 6 \\
\hline & $\begin{array}{l}\text { Рентабельность } \\
\text { инновационных проектов }\end{array}$ & 8 & 6 & 1 & 5 & 6 & 3 & 1 & 9 & 39 & 4 \\
\hline & Сумма & 99 & 109 & 29 & 58 & 64 & 57 & 49 & 110 & & \\
\hline
\end{tabular}


На следующем этапе предлагается провести сравнение динамических критериев нескольких организаций. В этом случае нами были выбраны способы ранжирования. В рамках процесса ранжирования предпочтение чаще всего отдают таксонометрическому методу и методу суммы мест [8]. Рейтинги, составленные на основе данных методов, позволяют произвести комплексную оценку эффективности функционирования экономических субъектов.

Вслед за этим необходимо сформировать фактические ранговые ряды движения показателей. Это подразумевает реализацию следующих шагов:

1) рассчитываются темпы роста показателей, характеризующих изменяющиеся условия функционирования предприятия;

2) рассчитывается ускорение изменения показателей и их величин;

3) показатели ранжируются по убыванию их ускорения, от наибольшего к наименьшему.

На заключительном проведем сравнение ранговых рядов на базе двух характеристик: метрических соотношений и инверсий полных рядов. Оценку близости рангов нами предлагается осуществить с использованием коэффициента ранговой корреляции по метрическим соотношениям.

Расчет коэффициента ранговой корреляции по метрическим соотношениям включает следующие этапы:

- сопоставление каждого показателя и его порядкового номера (ранга) по возрастанию или убыванию;

- определение разности рангов каждой пары сопоставляемых значений $(R d)$;

- возведение в квадрат каждой разности и суммирование полученных результатов;

- вычисление коэффициента корреляции по метрическим соотношениям на основе следующей формулы:

$$
C M R=1-\frac{6 \cdot \sum R d^{2}}{n\left(n^{2}-1\right)}
$$


Также нами предлагается рассчитать ранговую корреляцию по инверсиям. Вычисление коэффициента ранговой корреляции по инверсиям определяется как разность вероятностей совпадения и инверсии в рангах.

Вычисление коэффициента ранговой корреляции по инверсиям будет произведено по формуле:

$$
R C I=\frac{C(x)-I(y)}{n \frac{(n-1)}{2}},
$$

где $C(x)$ - число совпадений,

$I(y)$ - число инверсий,

$n$ - объем выборки.

Значения по всем блокам динамических показателей за три года для трех выбранных нами гостиничных организаций г. Сочи представлены в табл. 2. Выбор данных организаций обусловлен общей категорийной принадлежностью, сопоставимым объемом номерного фонда и близостью в местоположении. Данные факторы позволяют рассматривать выбранные гостиничные организации как конкурирующие, а также обосновывают возможность их сравнения [14].

Таблица 2.

Показатели, характеризующие инновационный потенциал гостиничных организаций г. Сочи в период 2014-2016 гг.

\begin{tabular}{|c|c|c|c|c|c|c|c|c|c|c|}
\hline \multirow[b]{2}{*}{ № } & \multirow[b]{2}{*}{ Показатели } & \multicolumn{3}{|c|}{$\begin{array}{c}\text { Организа- } \\
\text { ция A }\end{array}$} & \multicolumn{3}{|c|}{$\begin{array}{c}\text { Организа- } \\
\text { ция В }\end{array}$} & \multicolumn{3}{|c|}{$\begin{array}{c}\text { Организа- } \\
\text { ция C }\end{array}$} \\
\hline & & 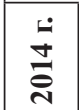 & $\stackrel{\dot{n}}{\stackrel{\sim}{2}}$ & 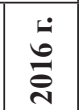 & $\underset{\dot{d}}{\dot{9}}$ & 茪 & 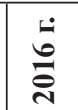 & $\underset{\dot{d}}{\stackrel{\dot{9}}{\dot{\theta}}}$ & $\stackrel{\dot{n}}{\stackrel{2}{2}}$ & 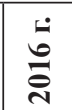 \\
\hline \multicolumn{11}{|c|}{ Основные показатели } \\
\hline 1 & Поток турь & 60,1 & 55 & 51,7 & 45,2 & 37,2 & 35,9 & 35,8 & 31,2 & 30,1 \\
\hline 2 & $\begin{array}{l}\text { Выручка } \\
\text { номеро-н }\end{array}$ & 3000 & 4000 & 5600 & 3200 & 2700 & 2500 & 3800 & 3500 & 27 \\
\hline 3 & $\begin{array}{l}\text { Коэффиі } \\
\text { номерно }\end{array}$ & 61,7 & 54,5 & 51,3 & 42,1 & 39,1 & 35,8 & 39,4 & 30,5 & 29,2 \\
\hline 4 & $\begin{array}{l}\text { Средняя длительность } \\
\text { пребывания на } 1 \text { номер, } \\
\text { дней }\end{array}$ & 5,2 & 3,5 & 3,4 & 4,1 & 3,1 & 2,5 & 2,5 & 2,3 & 1,9 \\
\hline
\end{tabular}


Окончание табл. 2.

\begin{tabular}{|c|c|c|c|c|c|c|c|c|c|c|}
\hline 5 & $\begin{array}{l}\text { Прибыль в расчете на } 1 \\
\text { номер, тыс. руб. }\end{array}$ & 2000 & 1450 & 1400 & 1200 & 850 & 900 & 1100 & 850 & 810 \\
\hline 6 & $\begin{array}{l}\text { Рентабельность оказания } \\
\text { гостиничных услуг, \% }\end{array}$ & 20,2 & 15,7 & 10,1 & 12,1 & 10,3 & 9,4 & 14,5 & 11,1 & 8,1 \\
\hline 7 & $\begin{array}{l}\text { Доход на номер, тыс. } \\
\text { руб. }\end{array}$ & 3700 & 3500 & 3100 & 2900 & 2500 & 2100 & 2050 & 1500 & 195 \\
\hline 8 & $\begin{array}{l}\text { Средний доход на гостя, } \\
\text { тыс. руб. }\end{array}$ & 5100 & 4200 & 3900 & 3150 & 2950 & 2400 & 2900 & 2700 & 255 \\
\hline 9 & $\begin{array}{l}\text { Затраты в расчете на } 1 \\
\text { номеро-ночь, тыс.руб. }\end{array}$ & 2500 & 1900 & 1500 & 1900 & 1300 & 1200 & 1700 & 1500 & 120 \\
\hline \multicolumn{11}{|c|}{ Показатели обеспечения } \\
\hline 10 & $\begin{array}{l}\text { Затраты на коммуналь- } \\
\text { ные услуги, млн. руб. }\end{array}$ & 41,5 & 35,9 & 33,6 & 33,5 & 27,5 & 25,7 & 28,3 & 25,9 & 24, \\
\hline 11 & $\begin{array}{l}\text { Объем услуг связи, млн. } \\
\text { руб. }\end{array}$ & 2,2 & 1,7 & 1,6 & 1,9 & 1,5 & 1,1 & 0,9 & 0,5 & 0,6 \\
\hline 12 & $\begin{array}{l}\text { Затраты на прочие услу- } \\
\text { ги, млн. руб. }\end{array}$ & 21,3 & 16,8 & 17,1 & 18,5 & 13,4 & 12,2 & 12,5 & 9,8 & 9,4 \\
\hline 13 & $\begin{array}{l}\text { Выручка от реализации } \\
\text { продукции обществен- } \\
\text { ного питания, млн. руб. }\end{array}$ & 171,2 & 165,8 & 161,1 & 154,7 & 144,5 & 143,9 & 19,2 & 7,5 & 110 \\
\hline 14 & $\begin{array}{l}\text { Выручка от реализации } \\
\text { дополнительных услуг, } \\
\text { млн. руб. }\end{array}$ & 18,5 & 15,4 & 14,8 & 15,4 & 9,7 & 8,9 & 8,5 & 7,5 & 7,9 \\
\hline \multicolumn{11}{|c|}{ Показатели эффективности осуществления инновационной деятельности } \\
\hline 15 & $\begin{array}{l}\text { Капитальные вложение } \\
\text { на инновационную дея- } \\
\text { тельность, млн. руб.; }\end{array}$ & 1,4 & 0,7 & 0,6 & 0,9 & 0,4 & 0,3 & 0,5 & 0,3 & 0,3 \\
\hline 16 & $\begin{array}{l}\text { Чистая текущая стои- } \\
\text { мость инновационных } \\
\text { проектов, млн. руб.; }\end{array}$ & 0,9 & 0,6 & 0,4 & 0,7 & 0,3 & 0,1 & 0,3 & 0,2 & 0,2 \\
\hline 17 & $\begin{array}{l}\text { Окупаемость инноваци- } \\
\text { онных проектов, дней; }\end{array}$ & 251 & 295 & 316 & 285 & 325 & 330 & 194 & 220 & 225 \\
\hline 18 & $\begin{array}{l}\text { Рентабельность иннова- } \\
\text { ционных проектов, \%. }\end{array}$ & 28,1 & 25,6 & 22,2 & 29,2 & 29,5 & 27,9 & 30,1 & 25,3 & 24,5 \\
\hline
\end{tabular}

Произведем расчет коэффициентов ранговой корреляции по метрическим соотношениям и по инверсиям трёх гостиничных организаций г. Сочи за период 2014-2016 гг. (табл. 3, 4, 5).

Для оценки ИП нами был выбран метод суммы мест. Анализируемые значения любого показателя следует упорядочить в поряд- 
ке убывания, определяя при этом занимаемое им место. Величина суммы полученных мест обратно пропорционально детерминирует полученный результат.

Исходная информация при использовании данного метода представлена в виде матрицы:

$$
X=\left(\begin{array}{rrrr}
x_{12} & x_{12} & x_{13 \ldots \ldots} & x_{1 v} \\
x_{21} & x_{22} & x_{23} \ldots \ldots & x_{1 v} \\
x_{31} & x_{32} & x_{33 \ldots \ldots} \ldots & x_{1 v} \\
\ldots & \ldots & \ldots & \ldots \ldots \ldots \\
x_{w 1} & x_{w 2} & x_{w 3} \ldots \ldots & x_{w v}
\end{array}\right),
$$

где $v$ - число рассчитываемых показателей;

$w$ - число гостиничных организаций.

Таблицуа 3.

Расчет коэффициентов ранговой корреляции (метрические соотношения

и инверсии) гостиничных организаций г. Сочи, 2014 г.

\begin{tabular}{|c|c|c|c|c|c|c|c|c|c|c|c|c|}
\hline \multirow[b]{2}{*}{ 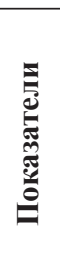 } & \multicolumn{4}{|c|}{ Организация А } & \multicolumn{4}{|c|}{ Организация В } & \multicolumn{4}{|c|}{ Организация С } \\
\hline & 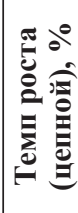 & 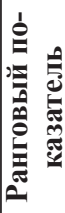 & 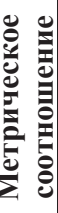 & 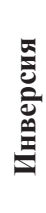 & 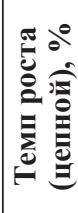 & 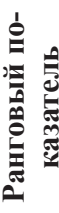 & 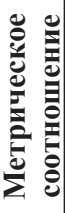 & 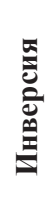 & 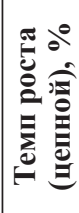 & 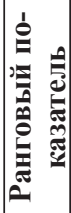 & 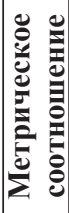 & 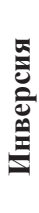 \\
\hline 1 & 132,1 & 14 & 3 & 2 & 127,3 & 13 & 2 & 9 & 142,1 & 4 & 1 & 8 \\
\hline 2 & 123,5 & \begin{tabular}{|l|}
17 \\
\end{tabular} & 3 & 3 & 141,6 & 9 & 1 & 6 & 122,6 & 11 & 2 & 6 \\
\hline 3 & 129,1 & 15 & 2 & 1 & 118,6 & 16 & 3 & 2 & 118,3 & 14 & 1 & 9 \\
\hline 4 & 152,9 & 5 & 2 & 1 & 164 & 3 & 1 & 8 & 113,6 & \begin{tabular}{|l|}
15 \\
\end{tabular} & 3 & 0 \\
\hline 5 & 137,0 & 13 & 2 & 1 & 114,3 & 17 & 3 & 2 & 129,4 & 8 & 1 & 8 \\
\hline 6 & 139,3 & 10 & 2 & 1 & 118,7 & 15 & 3 & 2 & 155,9 & 2 & 1 & 7 \\
\hline 7 & 151,0 & 6 & 1 & 0 & 142,9 & 8 & 2 & 0 & 111,4 & 16 & 3 & 0 \\
\hline 8 & 149,1 & 7 & 1 & 7 & 124 & 14 & 3 & 3 & 120,3 & 12 & 2 & 5 \\
\hline 9 & 148,8 & 8 & 1 & 0 & 139,7 & 11 & 2 & 0 & 106,3 & 17 & 3 & 4 \\
\hline 10 & 160,2 & 3 & 1 & 2 & 154,4 & 4 & 2 & 0 & 124,7 & 10 & 3 & 1 \\
\hline 11 & 157,1 & 4 & 1 & 9 & 146,2 & 7 & 2 & 0 & 128,6 & 9 & 3 & 0 \\
\hline 12 & 138,3 & 12 & 1 & 1 & 131,2 & 12 & 1 & 6 & 133,2 & 6 & 3 & 0 \\
\hline 13 & 142,1 & 9 & 2 & 3 & 149,6 & 5 & 1 & 8 & 118,7 & 13 & 3 & 0 \\
\hline 14 & 128,5 & 16 & 3 & 8 & 149,5 & 6 & 1 & 7 & 130,8 & 7 & 2 & 4 \\
\hline
\end{tabular}


Окончание табл. 3.

\begin{tabular}{|c|c|c|c|c|c|c|c|c|c|c|c|c|}
\hline 15 & 233,3 & 1 & 1 & 10 & 180,1 & 1 & 1 & 10 & 250 & 1 & 1 & 2 \\
\hline 16 & 138,5 & 11 & 3 & 8 & 140,1 & 10 & 2 & 0 & 150 & 3 & 1 & 2 \\
\hline 17 & 83,7 & 18 & 1 & 2 & 95,3 & 18 & 1 & 5 & 77,6 & 18 & 1 & 3 \\
\hline 18 & 180,1 & 2 & 1 & 6 & 165,9 & 2 & 1 & 9 & 135,1 & 5 & 3 & 2 \\
\hline $\begin{array}{c}\text { Сумма метри- } \\
\text { ческих соотно- } \\
\text { шений }\end{array}$ & & & 31 & & & & 32 & & & & 37 & \\
\hline СМR & & & 0,24 & & & & 0,47 & & & & 0,41 & \\
\hline Сумма инверсий & & & & 65 & & & & 77 & & & & 61 \\
\hline RСІ & & & & 0,29 & & & & 0,19 & & & & 0,33 \\
\hline
\end{tabular}

Таблица 4.

Расчет коэффициентов ранговой корреляции (метрические соотношения и инверсии) гостиничных организаций г. Сочи, 2015 г.

\begin{tabular}{|c|c|c|c|c|c|c|c|c|c|c|c|c|}
\hline \multirow{3}{*}{ 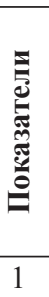 } & \multicolumn{4}{|c|}{ Организация А } & \multicolumn{4}{|c|}{ Организация В } & \multicolumn{4}{|c|}{ Организация C } \\
\hline & 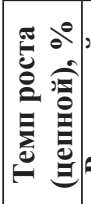 & 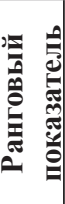 & 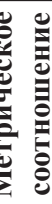 & 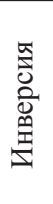 & 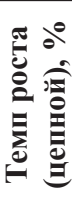 & 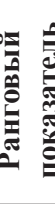 & & 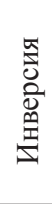 & 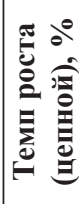 & & 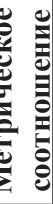 & 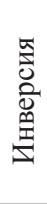 \\
\hline & \begin{tabular}{|l|}
91,8 \\
\end{tabular} & 5 & 1 & 9 & 75,6 & 10 & 3 & 1 & 87,2 & 9 & 2 & 8 \\
\hline 2 & 133,3 & 1 & 1 & 8 & 70,9 & 13 & 3 & 2 & 92,1 & 4 & 2 & 6 \\
\hline 3 & 88,3 & 7 & 2 & 4 & 85,2 & 6 & 1 & 2 & \begin{tabular}{|l|l}
77,4 \\
\end{tabular} & 12 & 3 & 9 \\
\hline 4 & $\mid 67,3$ & 16 & 3 & 2 & 86,2 & 5 & 1 & 2 & 92 & 5 & 1 & 1 \\
\hline 5 & 72,5 & 15 & 3 & 3 & 93,7 & 3 & 1 & 4 & 77,3 & 13 & 2 & 2 \\
\hline 6 & 77,7 & 12 & 1 & 7 & 68,4 & 15 & 3 & 0 & 76,6 & 14 & 2 & 4 \\
\hline 7 & 94,6 & 4 & 1 & 5 & 82,1 & 8 & 2 & 1 & 73,2 & 15 & 3 & 4 \\
\hline 8 & 82,4 & 10 & 3 & 5 & 78,9 & 9 & 2 & 0 & \begin{tabular}{|l}
93,1 \\
\end{tabular} & 3 & 1 & 0 \\
\hline 9 & 76 & 14 & 3 & 4 & 72,4 & 12 & 2 & 10 & 88,3 & 7 & 1 & 6 \\
\hline 10 & 86,5 & 8 & 3 & 1 & 93,4 & 4 & 1 & 6 & 91,5 & 6 & 2 & 8 \\
\hline 11 & 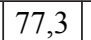 & 13 & 1 & 6 & 63,0 & 16 & 2 & 3 & 55,6 & 18 & 3 & 1 \\
\hline 12 & 78,9 & 11 & 1 & 0 & 44,4 & 17 & 3 & 2 & 78,4 & 11 & 1 & 2 \\
\hline 13 & 96,8 & 3 & 2 & 0 & 42,9 & 18 & 3 & 2 & \begin{tabular}{|l}
98,6 \\
\end{tabular} & 2 & 1 & 2 \\
\hline 14 & 83,2 & 9 & 3 & 1 & 114 & 1 & 1 & 1 & 88,2 & 8 & 2 & 3 \\
\hline 15 & 50 & 18 & 3 & 2 & 101 & 2 & 1 & 4 & 60,0 & 17 & 2 & 7 \\
\hline 16 & 66,7 & 17 & 3 & 2 & 75,5 & 11 & 1 & 4 & 66,7 & 16 & 2 & 8 \\
\hline 17 & 117,5 & 2 & 2 & 1 & 70,8 & 14 & 3 & 6 & 113,4 & 1 & 1 & 10 \\
\hline 18 & $\mid 91,1$ & 6 & 1 & 1 & 85,1 & 7 & 2 & 8 & \begin{tabular}{|l|}
84,1 \\
\end{tabular} & 10 & 3 & 0 \\
\hline
\end{tabular}


Окончание табл. 4.

\begin{tabular}{|c|c|c|c|c|c|c|c|c|c|c|c|c|}
\hline $\begin{array}{c}\text { Сумма метри- } \\
\text { ческих соотно- } \\
\text { шений }\end{array}$ & & 37 & & & & 35 & & & & 34 & \\
\hline CMR & & & 0,15 & & & & 0,05 & & & & 0,03 & \\
\hline Сумма инверсий & & & & 61 & & & & 58 & & & & 81 \\
\hline RCI & & & & 0,33 & & & & 0,37 & & & & 0,15 \\
\hline
\end{tabular}

Таблицุа 5.

Расчет коэффициентов ранговой корреляции (метрические соотношения и инверсии) гостиничных организаций г. Сочи, 2016 г.

\begin{tabular}{|c|c|c|c|c|c|c|c|c|c|c|c|c|}
\hline \multirow[b]{2}{*}{ 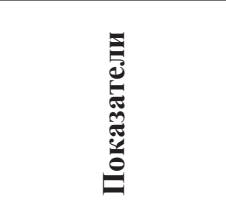 } & \multicolumn{4}{|c|}{ Организация А } & \multicolumn{4}{|c|}{ Организация В } & \multicolumn{4}{|c|}{ Организация С } \\
\hline & 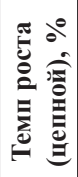 & 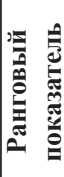 & 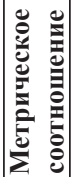 & 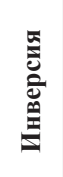 & 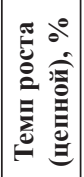 & 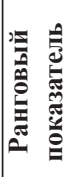 & 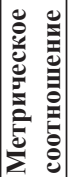 & 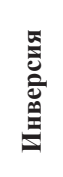 & 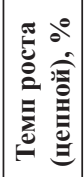 & 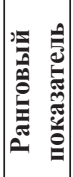 & 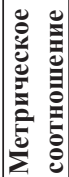 & 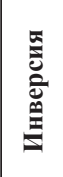 \\
\hline 1 & 93,7 & 10 & 2 & 5 & 80,7 & 14 & 3 & 0 & 96,5 & 9 & 1 & 2 \\
\hline 2 & 140 & 1 & 1 & 0 & 105,8 & 2 & 2 & 3 & 77,1 & 17 & 3 & 5 \\
\hline 3 & 94,2 & 8 & 1 & 3 & 91,4 & 9 & 2 & 6 & 95,7 & 11 & 3 & 0 \\
\hline 4 & 97,1 & 5 & 1 & 1 & 84 & 12 & 2 & 6 & 82,6 & 15 & 3 & 8 \\
\hline 5 & 96,6 & 6 & 1 & 2 & 81,4 & 13 & 3 & 8 & 95,3 & 12 & 2 & 0 \\
\hline 6 & 64,3 & 18 & 2 & 7 & 92,3 & 7 & 1 & 2 & 73,0 & 18 & 2 & 0 \\
\hline 7 & 88,6 & 13 & 3 & 9 & 93,5 & 6 & 2 & 0 & 130,1 & 1 & 1 & 2 \\
\hline 8 & 92,9 & 12 & 1 & 2 & 73,3 & 17 & 3 & 7 & 94,4 & 13 & 2 & 5 \\
\hline 9 & 78,9 & 16 & 2 & 4 & 91 & 11 & 1 & 3 & 80,1 & 16 & 2 & 6 \\
\hline 10 & 93,6 & 11 & 2 & 4 & 99,6 & 4 & 1 & 0 & 93,1 & 14 & 3 & 8 \\
\hline 11 & 94,1 & 9 & 3 & 9 & 91,8 & 8 & 2 & 0 & 120,2 & 2 & 1 & 3 \\
\hline 12 & 101,8 & 3 & 1 & 0 & 75 & 16 & 3 & 8 & 95,9 & 10 & 2 & 4 \\
\hline 13 & 97,2 & 4 & 1 & 2 & 33,3 & 18 & 3 & 0 & 99,1 & 7 & 2 & 4 \\
\hline 14 & 96,1 & 7 & 3 & 0 & 101,5 & 3 & 1 & 7 & 105,3 & 3 & 1 & 2 \\
\hline 15 & 85,7 & 15 & 3 & 0 & 94,6 & 5 & 1 & 5 & 100 & 6 & 2 & 0 \\
\hline 16 & 66,7 & 17 & 3 & 0 & 80,6 & 15 & 2 & 6 & 100,1 & 5 & 1 & 3 \\
\hline 17 & 107,1 & 2 & 2 & 0 & 105,9 & 1 & 1 & 3 & 102,3 & 4 & 3 & 6 \\
\hline 18 & 86,7 & 14 & 3 & 9 & 91,3 & 10 & 2 & 0 & 96,8 & 8 & 1 & 2 \\
\hline $\begin{array}{l}\text { Сумма метриче- } \\
\text { ских соотношений }\end{array}$ & & & 35 & & & & 35 & & & & 35 & \\
\hline CMR & & & 0,05 & & & & 0,31 & & & & $-0,25$ & \\
\hline Сумма инверсий & & & & 57 & & & & 64 & & & & 60 \\
\hline RCI & & & & 0,39 & & & & 0,43 & & & & 0,35 \\
\hline
\end{tabular}


Следует отметить наличие снижения как основных экономических показателей, так и показателей обеспечения и осуществления инновационной деятельности всех трех организаций в период 2015-2016 гг.

Показатель оценки инновационного потенциала гостиничных организаций г. Сочи, основанный на двух коэффициентах ранговой корреляции для данного периода времени, предлагается рассчитать по формуле:

$$
R V I P=\frac{(1+C M R) \times(1+R C I)}{4},
$$

Методика выявления показателя оценки инновационного потенциала на основе корреляционного анализа, по нашему мнению, необходима для детерминации тесноты корреляционных метрических соотношений и инверсий групп показателей, составляющих содержание исследуемого понятия.

Базу данной методики представляют конкретные показатели, находящие применение на практике, а также способные наиболее полно дать представление о фактическом уровне ИП гостиничных организаций.

Она обладает рядом преимуществ по сравнению с другими методиками оценки:

- имеется возможность системно оценить ИП гостиничных организаций путем использования наиболее значимых показателей, отражающих как полноту ресурсного обеспечения, так и успешность достижения поставленных целей его реализации;

- проводится оценка организаций с разным уровнем эффективности на основе отслеживания динамики движения показателей, а не их уровня;

- вычисление относительной величины делает возможным сопоставление натуральных и стоимостных показателей.

Представим результат произведенной нами оценки инновационного потенциала на основе многоцелевого подхода в графической интерпретации (рис. 3). 


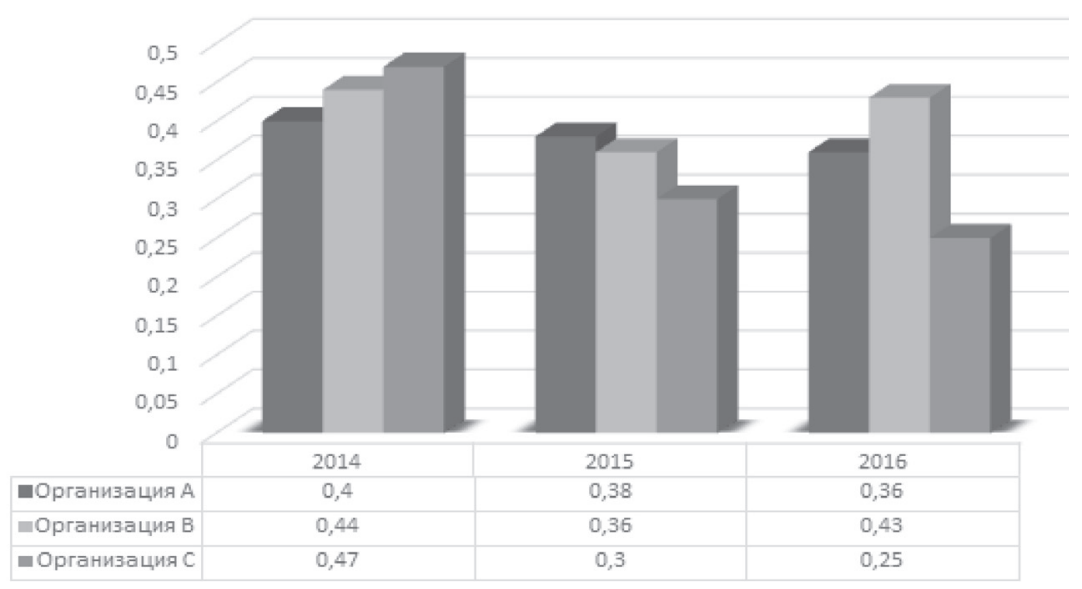

Рис. 3. Графическая интерпретация оценки инновационного потенциала гостиничных организаций г. Сочи, \%

Произведенные расчеты позволяют сделать вывод о достаточно высоком уровне инновационного потенциала гостиничных организации г. Сочи, который, однако, реализуется не в полном объеме и проявляет тенденцию к снижению в постолимпийский период. Повышение эффективности реализации инновационного потенциала, по нашему мнению, должно быть неразрывно связано с системными мероприятиями по развитию инновационного климата и инновационной структуры гостиничных организаций [5]. Реализация данных мероприятий способна оказать мультипликативный эффект [13] и обеспечить увеличение инновационного потенциала, эффективность его реализации, устойчивое экономическое развитие и уровень инновационной и инвестиционной привлекательности не только конкретных хозяйствующих субъектов, но также г. Сочи и Краснодарского края как успешных туристских дестинаций.

\section{Сиисок литературь}

1. Бендиков М.А., Хрусталев Е.Ю. Методологические основы исследования механизма инновационного развития в современной экономике // Менеджмент в России и за рубежом. 2007. № 2. С. 3-14. 
2. Бухонова С.М. Методика оценки и способы повышения эффективности использования инновационного потенциала организации / С.М. Бухонова, Ю.А. Дорошенко, И.А. Слабинская, Т.А. Шаповалова. Белгород, Изд-во БГТУ, 2012. 133 с.

3. Дежина И. Обеспечение эффективных механизмов осуществления инновационной деятельности в российской экономике. М.: ИЭПП, 2004. 152 c.

4. Дорошенко Ю.А. Управление инновациями: учебное пособие / Ю.А. Дорошенко, И.В. Сомина. Белгород: Изд-во БГТУ, 2011. 147 с.

5. Инновационный потенциал: современное состояние и перспективы развития / В.Г. Матвейкин, С.И. Дворецкий, Л.В. Минько, В.П. Тарасов, Л.Н. Чайникова, О.И. Летунова. М.: Изд-во Машиностроение-1, 2007. С.8.

6. Малахова Н.Н., Ушаков Д.С. Инновации в туризме и сервисе. Ростов н/Д: МарТ, 2008. 224 с.

7. Морозова Л.Э., Бортник О.А., Кравчук И.С. Экспертные методы и технологии комплексной оценки экономического и инновационного потенциала предприятий. Учебное пособие. М.: МГУПС, 2009. 81 с.

8. Недосекин А.О. Методологические основы моделирования финансовой деятельности с использованием нечетко-множественных описаний: Автореф. дис... д-ра экон. наук. Санкт-Петербург, 2003. 37 с.

9. Погостинская Н.Н. Системный подход в экономико-математическом моделировании: учеб. пособие. СПб: СПбГУЭФ, 1999. 74 с.

10. Руководство Осло: рекомендации по сбору и анализу данных по инновациям. Третье издание. Совместная публикация ОЭСР и Евростата. Москва: ЦИСН, 2010.

11. Сомина И.В. Методология и методические аспекты оценки экономической эффективности в сфере инновационной деятельности // Вестник Белгородского государственного технологического университета им. В.Г. Шухова. 2013. № 4. С. 142-145.

12. Управление инновациями в туристском бизнесе. Учебно-методическое пособие / Т.П. Левченко, В.А. Янюшкин, А.Ю. Яковлева-Чернышева. СПб.: Астерион, 2010. 204 с.

13. Фонотов А.Г. Россия: инновации и развитие. М.: Лаборатория знаний, 2012. С. 359. 
14. Якимович Г.Б., Пантюхова Т.С. Инновационная деятельность в туристическом бизнесе: монография. СПб: СПбГУСЭ, 2011. 175 с.

15. Фатхутдинов Р.А. Инновационный менеджмент: учебник для вузов. 6-е изд. СПб.: Питер, 2008. 448 с.

\section{References}

1. Bendikov M.A., Khrustalev E.Yu. Menedzhment v Rossii i za rubezhom. 2007. № 2, pp. 3-14.

2. Bukhonova S.M., Doroshenko Yu.A., Slabinskaya I.A., Shapovalova T.A. Metodika otsenki i sposoby povysheniya effektivnosti ispol'zovaniya innovatsionnogo potentsiala organizatsii [Methodology of evaluation and ways to improve the efficiency of using the innovative potential of the organization]. Belgorod, Izd-vo BGTU, 2012. $133 \mathrm{p}$.

3. Dezhina I. Obespechenie effektivnykh mekhanizmov osushchestvleniya innovatsionnoy deyatel'nosti v rossiyskoy ekonomike [Ensuring effective mechanisms for the implementation of innovation in the Russian economy]. M.: IEPP, 2004. 152 p.

4. Doroshenko Yu.A., Somina I.V. Upravlenie innovatsiyami [Innovation management]: a textbook. Belgorod: Izd-vo BGTU, 2011. $147 \mathrm{s.}$

5. Matveykin V.G., Dvoretskiy S.I., Min'ko L.V., Tarasov V.P., Chaynikova L.N., Letunova O.I. Innovatsionnyy potentsial: sovremennoe sostoyanie i perspektivy razvitiya [Innovative potential: current state and development prospects]. M.: Izd-vo Mashinostroenie-1, 2007. P. 8.

6. Malakhova N.N., Ushakov D.S. Innovatsii v turizme $i$ servise [Innovations in tourism and service]. Rostov n/D: MarT, 2008. 224 p.

7. Morozova L.E., Bortnik O.A., Kravchuk I.S. Ekspertnye metody i tekhnologii kompleksnoy otsenki ekonomicheskogo i innovatsionnogo potentsiala predpriyatiy [Expert methods and technologies of integrated assessment of the economic and innovative potential of enterprises]. M.: MGUPS, 2009. $81 \mathrm{p}$.

8. Nedosekin A.O. Metodologicheskie osnovy modelirovaniya finansovoy deyatel'nosti s ispol'zovaniem nechetko-mnozhestvennykh opisaniy [Methodological bases of modeling of financial activity with use of fuzzy-plural descriptions]. Sankt-Peterburg, 2003. 37 p. 
9. Pogostinskaya N.N. Sistemnyy podkhod v ekonomiko-matematicheskom modelirovanii [System approach in economic and mathematical modeling]. SPb: SPbGUEF, 1999. 74 p.

10. Rukovodstvo Oslo: rekomendatsii po sboru i analizu dannykh po innovatsiyam. Tret'e izdanie. Sovmestnaya publikatsiya OESR i Evrostata [The Oslo Guide: recommendations for the collection and analysis of innovation data. Third edition. Joint publication of OECD and Eurostat]. Moscow: TsISN, 2010

11. Somina I.V. Vestnik Belgorodskogo gosudarstvennogo tekhnologicheskogo universiteta im. V.G. Shukhova. 2013. № 4, pp. 142-145.

12. Levchenko T.P., Yanyushkin V.A., Yakovleva-Chernysheva A.Yu. Upravlenie innovatsiyami $v$ turistskom biznese [Management of innovations in the tourist business]. SPb.: Asterion, 2010. 204 p.

13. Fonotov A.G. Rossiya: innovatsii i razvitie [Russia: Innovation and Development]. M.: Laboratoriya znaniy, 2012. S. 359.

14. Yakimovich G.B., Pantyukhova T.S. Innovatsionnaya deyatel'nost' $v$ turisticheskom biznese [Innovative activity in the tourist business]. SPb: SPbGUSE, 2011. 175 p.

15. Fatkhutdinov R.A. Innovatsionnyy menedzhment [Innovative management]. SPb.: Piter, 2008. 448 s.

\section{ДАННЫЕ ОБ АВТОРАХ}

Левченко Татьяна Павловна, доктор экономических наук, профeccop

ФГБОУ ВО «Сочинский государственный университет» ул. Советская, 26А, г. Сочи, Краснодарский край, 354000 , Российская Федерации lekonst@mail.ru

Вареников Вячеслав Александрович, аспирант ФГБОУ ВО «Сочинский государственный университет» ул. Советская, 26А, г. Сочи, Краснодарский край, 354000 , Российская Федеращия www.vyacheslove@mail.ru 


\section{DATA ABOUT THE AUTHORS}

Levchenko Tat'yana Pavlovna, Doctor of Economics, Professor

Sochi State University

26A, Sovetskaya Str., Sochi, Krasnodar Territory, 354000, Russian Federation

lekonst@mail.ru

Varenikov Vyacheslav Aleksandrovich, Postgraduate Sochi State University

26A, Sovetskaya Str., Sochi, Krasnodar Territory, 354000, Russian Federation

www.vyacheslove@mail.ru 